\title{
IDENTIFYING HIGH RISK PREGNANCY AND ITS EFFECTIVENESS IN DETERMINING MATERNAL AND PERINATAL OUTCOME
}

\author{
Junu Shrestha ${ }^{1 *}$, Sangeeta Devi Gurung ${ }^{2}$, Anjali Subedi ${ }^{2}$, Chandani Pandey ${ }^{3}$
}

\begin{abstract}
Affiliation
1. Associate Professor, Department of Obstetrics and Gynaecology, Manipal College of Medical Sciences.

2. Assistant Professor, Department of Obstetrics and Gynaecology, Manipal College of Medical Sciences.

3. Postgraduate resident, Department of Obstetrics and Gynaecology, Manipal College of Medical Sciences
\end{abstract}

\section{ARTICLE INFO}

Received : 25 February, 2021

Accepted : 22 August, 2021

Published : 04 November 2021

(C) Authors retain copyright and grant the journal right of first publication with the work simultaneously licensed under Creative Commons Attribution License CC - BY 4.0 that allows others to share the work with an acknowledgment of the work's authorship and initial publication in this journal.

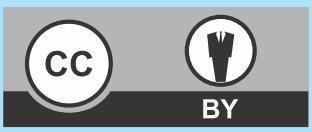

ORA 271

DOI: https://doi.org/10.3126/bjhs.v6i2.40360

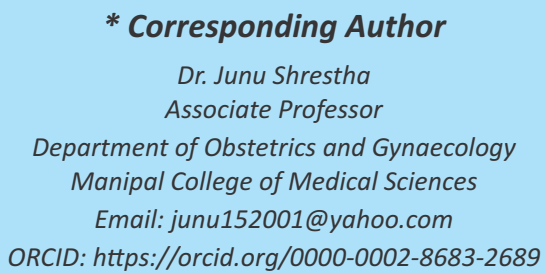

\section{Citation}

Junu Shrestha, Sangeeta Devi Gurung, Anjali Subedi, Chandani Pandey. Identifying High Risk Pregnancy and Its Effectiveness in determining Maternal and Perinatal Outcome. BJHS 2021;6(2)15. 1565-1572.

\section{ABSTRACT}

\section{Introduction}

Identification of high risk pregnancy can be done by using various scoring systems which is highly predictive in determining maternal and perinatal outcome.

\section{Objectives}

The objectives of the study were to identify high- risk pregnancy and to compare the maternal and perinatal outcome of high-risk with low-risk pregnancies.

\section{Methodology}

This study was conducted in the department of obstetrics and gynaecology, Manipal Teaching Hospital, Pokhara, from 1st August 2020 to 31st January 2021. Study included pregnant women coming for delivery after 28 weeks of gestation. Antenatal scoring system involving various risk factors, was used to stratify women as low-risk (score 0-3), high-risk (score 4-6) and extremely high-risk group ( score 27). All women were followed up in intrapartum and postpartum period and complications noted. Neonates were also followed up. Maternal and perinatal outcome of three groups were compared.

\section{Result}

There were $67.3 \%$ women in low-risk, $20 \%$ in high-risk and $12.7 \%$ in extremely high-risk groups. Operative deliveries were $89.9 \%$ in extremely high- risk, $77.9 \%$ in high- risk as compared to $51 \%$ in low- risk group. Maternal complications, total amount of blood loss and duration of hospital stay was more in extremely high-risk and high-risk pregnancies. Low birth weight was more common in extremely high risk (60\%) and high-risk (26\%) pregnancies compared to low- risk pregnancies (15\%). Neonates with low Apgar scores at 1 and 5 minutes were more in high-risk pregnancies. Thirty-two percent neonates in extremely high-risk pregnancy required neonatal intensive care admission which was significantly higher as compared to high-risk and low-risk pregnancies. Perinatal deaths were more frequent in extremely high-risk pregnancies.

\section{Conclusions}

Identifying high risk pregnancy using scoring system is useful to identify women at risk of developing maternal and perinatal complications.

\section{KEY WORDS}

Complications; High risk pregnancy; Pregnancy outcome; Perinatal deaths; Risk assessment. 


\section{INTRODUCTION}

High risk pregnancy is defined as the one in which there is presence of maternal or fetal factor that affects the pregnancy outcome - maternal or perinatal or both. ${ }^{1}$ High risk pregnancy constitutes about 15 to $40 \%$ of cases of pregnancy based on different studies. ${ }^{2-8}$ Maternal complications have been reported to be increased in pregnancies complicated by high risk factors. ${ }^{4,7,9}$ Likewise, perinatal outcome in terms of low birth weight, prematurity, birth asphyxia and perinatal deaths are also more in the high risk women. ${ }^{4,5,7,9,10,11}$

Therefore, identification of high risk pregnancy is prudent for improving the maternal and perinatal outcome. This could be made possible only through risk stratification of pregnant women during their antenatal care. Screening for risk factors can help in identifying the vulnerable group of pregnant women at the earliest so that extra care and appropriate intervention be given to improve the maternal and neonatal outcome. ${ }^{12}$ This can be especially useful for the antenatal care in the rural setup to make timely referrals of high risk pregnancies to tertiary centres.

Objectively defining high risk pregnancy by using scoring system can be useful for health care workers providing antenatal care especially in centres with limited resources. This can be true in country like ours. There are several systems for scoring of high risk pregnancy proposed by various authors. Nesbitt et al, Coopland et al, Hobel et al, Edward et al, Knox et al etc. are the different scoring system used in the past to score the high risk status of a woman during pregnancy. ${ }^{12-15}$ Many other authors have modified scoring system based on these systems. ${ }^{4,11,16}$

Nepal has made great leaps in maternal and perinatal health over two decades. ${ }^{17,18}$ Nevertheless, in order to meet the aspiring SDG target of reducing the MMR to 70 per 100,000 live births and preventable deaths of newborns to less than one percent by 2030, ${ }^{19}$ multifocal interventions need to be made, one of which is quality antenatal care and identification of high risk factors in pregnancy. Introducing a scoring system in antenatal care to identify high risk pregnancies seems to be a useful means to improve maternal and perinatal health.

Hence, this study was conducted with the aim to determine the use of scoring system to identify high risk pregnancies and compare the maternal and perinatal outcome of high risk pregnancies with that of low risk pregnancies.

\section{METHODOLOGY}

This was a prospective cross- sectional study that was conducted in the department of Obstetrics and Gynaecology, Manipal Teaching Hospital in Pokhara, Nepal. Study was conducted for a period of six months from 1st August 2020 to 31st January 2021after obtaining ethical approval.

Study participants were selected using convenient sampling technique. Those who met the inclusion criteria and consented to participate were included in the study. Patients who were lost to follow up were excluded. This study included the women presenting at the time of delivery, which included booked as well as unbooked cases.

\section{Inclusion criteria:}

All women presenting for delivery after 28 weeks of gestation

Booked as well as unbooked patients

All women willing to participate in the study

\section{Exclusion criteria:}

Pregnant women admitted before 28 weeks of gestation

\section{Sample size}

The sample size was calculated using the following formula for cross-sectional study.

$$
n=\frac{Z^{2} p(1-p)}{d^{2}}
$$

Where, $\mathrm{n}$ is the sample size, $\mathrm{Z}$ is the statistic corresponding to level of confidence, $P$ is expected prevalence and $d$ is precision (corresponding to effect size).

With estimated prevalence of about $25 \%$ high risk pregnancy taken from some studies conducted in Nepal, ${ }^{3}$ $Z=1.96$ at $95 \%$ level of confidence and $5 \%$ precision, minimum sample size was calculated to be 288 . However, a total of 700 cases were enrolled in the study during the study period.

\section{Ethical Consideration:}

Informed consent was taken from all participants after informing them about the nature of the study. Only those pregnant women willing to participate in the study were included. They were informed that they would have the right to withdraw from the study any time if they wished to do so. Privacy and confidentiality was maintained. Ethical approval was taken from the Institutional Review Committee prior to conducting the study.

\section{Data Collection}

Women presenting for delivery after 28 weeks of gestation were included in the study. Detailed history was taken. Their state of booking and the level of antenatal supervision were noted. Detailed general, systemic and obstetric examination was done. The risk scoring was done using modified antenatal scoring system used by Anand B et al. ${ }^{4}$ Few other risk factors (multiple pregnancy, post term pregnancy) that were missing were also added in this scoring system. The modified risk scoring system is given in table1.

Pregnant women were grouped as low risk with score of less than 3 , high risk if score was 4 to 6 and extremely high risk if score was $\geq 7$.

All the women were closely followed up during the intrapartum and postnatal period till discharge. Mode of delivery, intrapartum and postpartum complications, amount of blood loss, number of days of hospital stay were the variables that were studied. For perinatal outcome birth weight, Apgar score and need for neonatal admission and indication for admission, early perinatal deaths were also studied. 


\section{Data analysis}

All the data were noted in the proforma. Data entry was done in excel and all analysis were conducted using Stata/IC version 15.1 (StataCorp, College Station, Texas 77845 USA). Descriptive analysis of prevalence of high risk pregnancy, socio demographic characteristics, maternal outcomes and perinatal outcomes were done using percentage. For examining the association of continuous variables with risk categories, t-test was used, and for examining the association of categorical variables with risk categories, either chi-square test or fisher's exact tests were used as required. The $p$-value less than 0.05 were considered to be statistically significant.

\section{RESULTS}

Using modified antenatal risk scoring system, amongst 700 women, 471 (67.3\%) were low risk , 140 (20\%) high risk and $89(12.7 \%)$ were grouped as extremely high risk pregnancy.

There was no risk factor in 216 (30.9\%) pregnant women and had score zero. However, according to scoring system, they were grouped in low risk group. Common medical risk factors present were elderly gravida $(7.4 \%)$, urinary tract infection (3.9\%) and hypothyroidism (5.3\%). In terms of risk factors in relation to past obstetric factors, history of previous cesarean section $(20.6 \%)$ and previous abortion especially in first trimester (22\%) were very prevalent in pregnant women in this study. The obstetric risk factors of present pregnancy that were common were hypertensive disorders of pregnancy (15.4\%), oligohydramnios (9.7\%), Preterm labour and preterm prelabour rupture of membranes $(8.1 \%)$, anemia $(5.7 \%)$, malpresentation at term (4.9\%) and intrauterine growth restrictions (2.5\%).

Table1: Modified High Risk Pregnancy Scoring System

\begin{tabular}{|c|c|c|c|c|c|}
\hline Medical Risk Factors & Score & Past Obstetric factors & Score & Present obstetric risk factors & Score \\
\hline Age $<16$ & 2 & Infertility & 1 & PPROM & 4 \\
\hline Age $>35$ & 2 & ART conception & 2 & Preterm labour & 4 \\
\hline Parity $>4$ & 3 & Abortions (first trimester) & 1 & Post term pregnancy & 2 \\
\hline Maternal weight less $(\mathrm{BMI}<19)$ & 3 & Abortion (second trimester) & 2 & Polyhydramnios (AFI > 24) & 4 \\
\hline Maternal weight more (BMI>28) & 3 & Preterm births & 2 & IUGR & 4 \\
\hline Heart disease (NYHA III \& IV)) & 4 & Recurrent spontaneous abortions & 3 & Rhesus isoimmunization & 4 \\
\hline Heart disease (NYHA I \& II) & 1 & $\begin{array}{l}\text { Family history of recurrent } \\
\text { abortions }\end{array}$ & 1 & Malpresentation at term / delivery & 4 \\
\hline $\begin{array}{l}\text { Moderate to severe renal disease } \\
\text { (creatinine }>1.5 \mathrm{mg} / \mathrm{dl} \text { ) }\end{array}$ & 4 & $\mathrm{PPH}$ & 3 & Vaginal bleeding first trimester & 2 \\
\hline $\begin{array}{l}\text { Chronic renal disease (creatinine } \\
>3 \mathrm{mg} / \mathrm{dl} \text { ) }\end{array}$ & 4 & Hypertension/eclampsia & 3 & Vaginal bleeding second trimester & 3 \\
\hline Pregestational DM & 4 & $\begin{array}{l}\text { Prolonged labour/ difficult } \\
\text { delivery }\end{array}$ & 4 & Mild anemia $(\mathrm{Hb}<10 \mathrm{gm} \%)$ & 1 \\
\hline Chronic hypertension & 3 & Still births/ neonatal deaths & 4 & Severe anemia $(\mathrm{Hb}<6 \mathrm{gm} \%)$ & 4 \\
\hline $\begin{array}{l}\text { Controlled epilepsy (seizure free for } \\
\text { at least } 1 \text { year before pregnancy) }\end{array}$ & 1 & Cesarean one delivery & 2 & $\begin{array}{l}\text { Intrahepatic cholestasis of } \\
\text { pregnancy }\end{array}$ & 4 \\
\hline $\begin{array}{l}\text { Uncontrolled epilepsy (recent } \\
\text { seizure episode) }\end{array}$ & 4 & Cesarean delivery more than one & 4 & Minor fetal anomaly & 1 \\
\hline $\begin{array}{l}\text { Hypothyroidism/hyperthyroidism } \\
\text { uncontrolled }\end{array}$ & 4 & $\begin{array}{l}\text { Fetal anomaly with heritable } \\
\text { genetic cause }\end{array}$ & 4 & Major fetal malformation & 4 \\
\hline $\begin{array}{l}\text { Hypothyroidism/hyperthyroidism } \\
\text { controlled }\end{array}$ & 1 & $\begin{array}{l}\text { Fetal anomaly not heritable } \\
\text { genetic cause }\end{array}$ & 1 & Placenta previa minor degree & 2 \\
\hline $\begin{array}{l}\text { Active immunological disease } \\
\text { (SLE, RA, systemic sclerosis, } \\
\text { vasculitis) }\end{array}$ & 4 & $\begin{array}{l}\text { Radioiodine ablation in past } 6 \\
\text { months }\end{array}$ & 1 & Placenta previa major degree & 4 \\
\hline $\begin{array}{l}\text { Immunological disease (inactive } \\
\text { for past } 6 \text { months) }\end{array}$ & 2 & Gynaecological disorders & 3 & Placental abruption grade 1 & 2 \\
\hline Tuberculosis & 2 & Uterine malformation & 3 & $\begin{array}{l}\text { Placental abruption grade } 2 \text { and } \\
\text { above }\end{array}$ & 4 \\
\hline $\begin{array}{l}\text { Pulmonary disease ( asthma, } \\
\text { bronchitis etc) }\end{array}$ & 2 & & & Morbid adherent placenta & 4 \\
\hline Smoking & 2 & & & Gestational hypertension & 2 \\
\hline Moderate alcohol use & 2 & & & Preeclampsia & 3 \\
\hline Brain tumor & 4 & & & Eclampsia & 4 \\
\hline Hepatitis Icterus decreasing & 1 & & & Oligohydramnios & 2 \\
\hline Hepatitis Icterus increasing & 4 & & & Abnormal UA Doppler & 3 \\
\hline Chronic disease like HIV & 4 & & & Absent or reverse diastolic flows & 4 \\
\hline Infection seropositive & 2 & & & Gestational diabetes & 3 \\
\hline $\begin{array}{l}\text { Active viral, fungal, bacterial, } \\
\text { protozoal disease }\end{array}$ & 4 & & & Twin Pregnancy uncomplicated & 2 \\
\hline \multirow[t]{2}{*}{ Urinary tract infection } & 2 & & & Twin Pregnancy complicated & 4 \\
\hline & & & & Higher order births & 4 \\
\hline \multicolumn{6}{|l|}{ Total Score } \\
\hline \multicolumn{2}{|l|}{ Low risk (0-3) } & \multicolumn{2}{|l|}{ High risk (4-6) } & Extremely high risk ( $\geq 7$ ) & \\
\hline
\end{tabular}




\section{Socio-demographic Variables, Antenatal Care and their Association with High Risk Groups}

The socio-demographic variables and antenatal care of the participants are presented in table 2 .

Majority of the participations belonged to Brahmin and Chhetri ethnic group. Educational status of most of them was upto secondary level in all three groups. Almost three quarters of the women were housewives in low and high risk group and about two third of them in extremely high risk group. Likewise, most of the women came from urban areas in all three groups of women. The difference in the sociodemographic variables in the different risk groups was not statistically significant.

While analyzing the antenatal supervision of these patients, it was found all the women had antenatal care even though the number of visits was less than four. Most of the women in all groups had been booked outside. Only, about one-third of the participants were booked at our centre in all three groups. Considering the number of visits, it was found that more than half of the participants had four or more antenatal visits and this was true for all three groups.
Maternal Outcome in Pregnant Women belonging to Different High Risk Groups

The maternal outcome of the pregnant women belonging to different high risk groups are presented in table 3.

Majority of the women in extremely high risk and high risk pregnancy were delivered by cesarean section. Nearly $90 \%$ of women belonging to extremely high risk group and $78 \%$ belonging to high risk group delivered via cesarean section compared to $51 \%$ of low risk pregnancy being delivered by cesarean section. This difference was found to be statistically significant.

Overall, 5.3\% of all participants developed complications following delivery. On comparing the maternal complications in different groups, it was found to be more in high risk (7.9\%) and extremely high risk group (10.1\%) compared to low risk group (3.6\%). This difference was also found to statistically significant.

Blood loss during delivery was also significantly more in the extremely high risk pregnancy and high risk group compared to low risk group. However, the need for blood transfusion though more in the high risk groups; was not statistically significant. Mean number of days of hospital

\begin{tabular}{|c|c|c|c|c|c|c|}
\hline \multirow[t]{2}{*}{ Variables } & \multirow[t]{2}{*}{ Labels } & Total & Low Risk & High Risk & $\begin{array}{l}\text { Extremely } \\
\text { High Risk }\end{array}$ & \multirow[t]{2}{*}{ p-value } \\
\hline & & $N=700$ & $N=471$ & $N=140$ & $\mathrm{~N}=\mathbf{8 9}$ & \\
\hline \multirow{6}{*}{$\begin{array}{l}\text { Ethnicity of } \\
\text { Women }\end{array}$} & Brahmin \& Chhetri & $386(55.1)$ & 268 (56.9) & $76(54.3)$ & $42(47.2)$ & \multirow[t]{6}{*}{0.02} \\
\hline & Dalit & $98(14.0)$ & $65(13.8)$ & $19(13.6)$ & $14(15.7)$ & \\
\hline & Janajati & $152(21.7)$ & $99(21.0)$ & $27(19.3)$ & $26(29.2)$ & \\
\hline & Madeshi & $13(1.9)$ & $5(1.1)$ & $7(5.0)$ & $1(1.1)$ & \\
\hline & Muslim & $16(2.3)$ & $13(2.8)$ & $0(0.0)$ & $3(3.4)$ & \\
\hline & Others & $35(5.0)$ & $21(4.5)$ & $11(7.9)$ & $3(3.4)$ & \\
\hline \multirow{2}{*}{$\begin{array}{l}\text { Place of } \\
\text { Residence }\end{array}$} & Rural & $228(32.6)$ & $153(32.5)$ & $52(37.1)$ & $23(25.8)$ & \multirow[t]{2}{*}{0.21} \\
\hline & Urban & $472(67.4)$ & $318(67.5)$ & 88 (62.9) & $66(74.2)$ & \\
\hline \multirow{4}{*}{$\begin{array}{l}\text { Education of } \\
\text { Women }\end{array}$} & None & $10(1.4)$ & $4(0.8)$ & $4(2.9)$ & $2(2.2)$ & \multirow[t]{4}{*}{0.31} \\
\hline & Primary and Secondary & $245(35.0)$ & $159(33.8)$ & $49(35.0)$ & $37(41.6)$ & \\
\hline & Higher Secondary & $246(35.1)$ & $172(36.5)$ & $44(31.4)$ & $30(33.7)$ & \\
\hline & Bachelor and Masters & $199(28.4)$ & $136(28.9)$ & $43(30.7)$ & $20(22.5)$ & \\
\hline \multirow{7}{*}{$\begin{array}{l}\text { Occupation of } \\
\text { Women }\end{array}$} & Housewife & $535(76.4)$ & 359 (76.2) & 110 (78.6) & $66(74.2)$ & \multirow[t]{7}{*}{0.07} \\
\hline & Professional & $65(9.3)$ & $42(8.9)$ & $12(8.6)$ & $11(12.4)$ & \\
\hline & Clerical & $33(4.7)$ & $23(4.9)$ & $9(6.4)$ & $1(1.1)$ & \\
\hline & Sales/Service & $40(5.7)$ & $32(6.8)$ & $4(2.9)$ & $4(4.5)$ & \\
\hline & Skilled manual & $13(1.9)$ & $7(1.5)$ & $2(1.4)$ & $4(4.5)$ & \\
\hline & Unskilled manual & $3(0.4)$ & $1(0.2)$ & $0(0.0)$ & $2(2.2)$ & \\
\hline & Agriculture & $11(1.6)$ & $7(1.5)$ & $3(2.1)$ & $1(1.1)$ & \\
\hline \multirow{3}{*}{$\begin{array}{l}\text { Place of } \\
\text { Antenatal care }\end{array}$} & MTH & $227(32.4)$ & $160(34.0)$ & $37(26.4)$ & $30(33.7)$ & \multirow[t]{3}{*}{0.26} \\
\hline & $\begin{array}{l}\text { Outside in Primary } \\
\text { centres }\end{array}$ & $188(26.9)$ & $127(27.0)$ & $43(30.7)$ & $18(20.2)$ & \\
\hline & $\begin{array}{l}\text { Outside in Tertiary } \\
\text { centres }\end{array}$ & $285(40.7)$ & 184 (39.1) & $60(42.9)$ & 41 (46.1) & \\
\hline $\begin{array}{l}\text { Number of } \\
\text { Antenatal Visits }\end{array}$ & $\leq 4$ visits & 304 (43.4) & $214(45.4)$ & $56(40)$ & $34(38.2)$ & 0.11 \\
\hline Antenatal Visits & $>4$ visits & $396(56.6)$ & $257(54.6)$ & $84(60)$ & $55(61.8)$ & \\
\hline
\end{tabular}

Figures in the parentheses indicate percentage. 
Table 3: Maternal Outcome in Pregnant Women belonging to Different High Risk Groups

\begin{tabular}{|c|c|c|c|c|c|c|}
\hline \multirow{2}{*}{\multicolumn{2}{|c|}{ Variables }} & Total & Low Risk & High Risk & & \multirow[t]{2}{*}{ p-value } \\
\hline & & $N=700$ & $N=471$ & $\mathbf{N}=\mathbf{1 4 0}$ & $\mathrm{N}=\mathbf{8 9}$ & \\
\hline \multirow{3}{*}{$\begin{array}{l}\text { Mode of } \\
\text { Delivery }\end{array}$} & Cesarean section & $429(61.3)$ & $240(51.0)$ & $109(77.9)$ & $80(89.9)$ & \multirow[t]{3}{*}{$<0.001$} \\
\hline & Vaginal delivery & $262(37.4)$ & $223(47.3)$ & $30(21.4)$ & $9(10.1)$ & \\
\hline & Assisted Vaginal delivery & $9(1.3)$ & $8(1.7)$ & $1(0.7)$ & $0(0.0)$ & \\
\hline \multicolumn{2}{|c|}{ Maternal Complications } & $37(5.3)$ & $17(3.6)$ & $11(7.9)$ & $9(10.1)$ & 0.013 \\
\hline \multicolumn{2}{|c|}{ Mean Blood loss during delivery (ml) } & $274.3( \pm 101.4)$ & $262.8( \pm 94.0)$ & $283.6( \pm 72.6)$ & $320.2( \pm 152.2)$ & $<0.001$ \\
\hline \multicolumn{2}{|c|}{ Need for Blood Transfusion } & $29(4.1)$ & $15(3.2)$ & $7(5.0)$ & $7(7.9)$ & 0.11 \\
\hline \multicolumn{2}{|c|}{ Duration of hospital stay(days) } & $3.8( \pm 2.1)$ & $3.4( \pm 1.6)$ & $4.3( \pm 2.0)$ & $5.5( \pm 3.1)$ & $<0.001$ \\
\hline
\end{tabular}

Data are presented as mean (SD) for continuous measures, and n (\%) for categorical measures.

stay in extremely high risk group was 5.5 days and compared to 4.3 days for high risk and 3.4 days for low risk group. This difference was statistically significant.

Commonest indication of cesarean section was previous cesarean delivery followed by fetal distress. Previous cesarean section was the commonest indication in high risk and extremely high risk pregnancies while fetal distress was the commonest for low risk pregnancy. Other indications were antepartum haemorrhage, malpresentation, labour dystocia, hypertensive disorders in pregnancy etc.

Maternal complications in different high risk pregnancy groups are presented table 4 .

Most common complication developed by patients was postpartum haemorrhage $(56.8 \%)$ followed by urinary complications (16.4\%). Postpartum haemorrhage was the commonest complication in all three groups. Other complications were puerperal pyrexia, rectus sheath haematoma, postpartum eclampsia etc. One patient in extremely high risk group developed postpartum haemorrhage which required peripartum hysterectomy.

\section{Neonatal Outcome in Pregnant Women belonging to Different High Risk Groups}

The neonatal outcome of the pregnant women belonging to different high risk groups are presented table 5 . Since there were five set of twins, the total number of neonates summed 705 .

In extremely high risk patients, nearly $60 \%$ of babies were low birth weight (<2500 gms) with $9 \%$ babies weighing less

Table 4: Maternal Complications in Different High Risk

Pregnancy Groups
\begin{tabular}{|l|l|l|l|l|}
\hline Maternal Complications & \multicolumn{1}{|c|}{ Total } & \multicolumn{1}{|c|}{ Low Risk } & High Risk & $\begin{array}{l}\text { Extremely } \\
\text { High Risk }\end{array}$ \\
\cline { 2 - 5 } & $\mathbf{N}=\mathbf{3 7}$ & $\mathbf{N}=\mathbf{1 7}$ & $\mathbf{N}=\mathbf{1 1}$ & $\mathbf{N}=\mathbf{9}$ \\
\hline Postpartum Haemorrhage & $21(56.8)$ & $14(82.4)$ & $3(27.3)$ & $4(44.4)$ \\
\hline $\begin{array}{l}\text { Peripartum hysterectomy } \\
\text { for PPH }\end{array}$ & $1(2.7)$ & $0(0.0)$ & $0(0.0)$ & $1(11.1)$ \\
\hline Postpartum eclampsia & $3(8.1)$ & $0(0.0)$ & $2(18.2)$ & $1(11.1)$ \\
\hline Puerperal pyrexia & $2(5.4)$ & $0(0.0)$ & $1(9.1)$ & $1(11.1)$ \\
\hline Placenta incerta & $2(5.4)$ & $0(0.0)$ & $19.1)$ & $1(11.1)$ \\
\hline $\begin{array}{l}\text { Rectus sheath } \\
\text { haematoma }\end{array}$ & $2(5.4)$ & $0(0.0)$ & $2(18.2)$ & $0(0.0)$ \\
\hline Urinary complications & $6(16.4)$ & $3(17.6)$ & $2(18.2)$ & $1(11.1)$ \\
\hline
\end{tabular}

Figures in parentheses indicate percentage. than $1500 \mathrm{gms}$. This was significantly high compared to only $15 \%$ and $24 \%$ neonates being low birth weight in low risk and high risk groups respectively. Likewise, higher proportion of neonates in extremely high risk group had Apgar score at 1 and 5 minutes less than 7. This was also found to be statistically significant.

Larger proportion of neonates $(34.8 \%)$ in extremely high risk group required admission in the neonatal intensive care unit (NICU) compared to $9.2 \%$ in high risk and $4.5 \%$ in low risk group. Perinatal deaths (stillbirths and early neonatal deaths) were also significantly more in the extremely high risk group compared to low risk and high risk groups.

The neonatal complications in different high risk pregnancy groups are presented in table 6.

Table 5: Neonatal Outcome in Pregnant Women belonging to Different High Risk Groups

\begin{tabular}{|c|c|c|c|c|c|c|}
\hline \multirow[t]{2}{*}{ Variables } & \multirow[t]{2}{*}{ Labels } & Total & Low Risk & High Risk & $\begin{array}{l}\text { Extremely } \\
\text { High Risk }\end{array}$ & p-value \\
\hline & & $N=705$ & $\mathrm{~N}=471$ & $\mathrm{~N}=142$ & $\mathrm{~N}=92$ & \\
\hline \multirow{4}{*}{$\begin{array}{l}\text { Birth Weight } \\
\text { Categories }\end{array}$} & $<1000 \mathrm{gm}$ & $1(0.1)$ & $0(0.0)$ & $0(0.0)$ & $1(1.1)$ & \multirow[t]{4}{*}{$<0.001$} \\
\hline & $1000-1500 \mathrm{gm}$ & $9(1.3)$ & $0(0.0)$ & $2(1.4)$ & $7(7.6)$ & \\
\hline & $1500-2500 \mathrm{gm}$ & 152 (21.6) & $69(14.6)$ & $35(24.6)$ & $48(52.2)$ & \\
\hline & $>2500 \mathrm{gm}$ & $543(77.0)$ & $402(85.4)$ & $105(73.9)$ & $36(39.1)$ & \\
\hline \multirow{2}{*}{$\begin{array}{l}\text { Apgar at one } \\
\text { minute }\end{array}$} & $<7$ & $25(3.5)$ & $10(2.1)$ & $5(3.5)$ & $10(10.9)$ & \multirow[t]{2}{*}{$<0.001$} \\
\hline & $\geq 7$ & 680 (96.5) & 461 (97.9) & $137(96.5)$ & $82(89.1)$ & \\
\hline \multirow{2}{*}{$\begin{array}{l}\text { Apgar at five } \\
\text { minutes }\end{array}$} & $<7$ & $8(1.1)$ & $1(0.2)$ & $3(2.1)$ & $4(4.3)$ & \multirow[t]{2}{*}{0.001} \\
\hline & $\geq 7$ & 697 (98.9) & \begin{tabular}{|l|}
$470(99.8)$ \\
\end{tabular} & $139(97.9)$ & $88(95.7)$ & \\
\hline Admission at NICU & & $66(9.4)$ & $21(4.5)$ & $13(9.2)$ & $32(34.8)$ & $<0.001$ \\
\hline $\begin{array}{l}\text { Duration of NICU } \\
\text { stay (days) }\end{array}$ & & $5.6( \pm 3.1)$ & $6.0( \pm 2.7)$ & $5.8( \pm 4.1)$ & $5.2( \pm 3.0)$ & 0.63 \\
\hline \multirow[t]{3}{*}{ Perinatal Outcome } & Live Births & 690 (97.9) & 470 (99.8) & 139 (97.9) & $81(88.0)$ & \multirow[t]{3}{*}{$<0.001$} \\
\hline & Still Births & $2(0.3)$ & $1(0.2)$ & $0(0.0)$ & $1(1.1)$ & \\
\hline & $\begin{array}{l}\text { Early Neonatal } \\
\text { Deaths }\end{array}$ & $13(1.8)$ & $0(0.0)$ & $3(2.1)$ & $10(10.9)$ & \\
\hline
\end{tabular}

Data are presented as mean (SD) for continuous measures, and $\mathrm{n}(\%)$ for categorical measures.

The most common reason for admission in Neonatal Intensive Care Unit (NICU) was prematurity followed by neonatal sepsis in the study population. Mostly prematurity was the common indication for NICU admission in extremely high risk group (62.5\%). Other indications were neonatal jaundice, low birth weight, meconium aspiration syndrome, birth asphyxia etc.

\section{DISCUSSION}

Identifying high risk pregnancy can ensure appropriate and timely care to the women, which in turn ensures optimal maternal and perinatal outcome. This could be made 
possible using objectively defined scoring systems. Review of studies done in different settings using different scoring systems has found good sensitivity of these systems in predicting perinatal outcome. $^{20}$

Table 6: Neonatal Intensive Care Unit Admission in Different High Risk Pregnancy Groups

\begin{tabular}{|l|l|l|l|l|}
\hline \multirow{2}{*}{ Indications for NICU Admission } & \multicolumn{1}{|c|}{ Total } & \multicolumn{1}{|c|}{$\begin{array}{c}\text { Low } \\
\text { Risk }\end{array}$} & High Risk & $\begin{array}{l}\text { Extremely } \\
\text { High Risk }\end{array}$ \\
\cline { 2 - 5 } & \multicolumn{1}{|c|}{$\mathbf{N = 6 6}$} & $\mathbf{N}=\mathbf{2 1}$ & \multicolumn{1}{|c|}{$\mathbf{N = 1 3}$} & \multicolumn{1}{|c|}{$\mathbf{3 2}$} \\
\hline Prematurity & $25(37.9)$ & $1(4.8)$ & $4(30.8)$ & $20(62.5)$ \\
\hline Birth asphyxia & $5(7.6)$ & $3(14.3)$ & $1(7.7)$ & $1(3.1)$ \\
\hline Meconium aspiration syndrome & $3(4.5)$ & $3(14.3)$ & $0(0.0)$ & $0(0.0)$ \\
\hline Early onset neonatal sepsis & $10(15.2)$ & $7(33.3)$ & $3(23.1)$ & $0(0.0)$ \\
\hline Congenital pneumonia & $2(3.0)$ & $1(4.8)$ & $0(0.0)$ & $1(3.1)$ \\
\hline Transient tachypnea of newborn & $3(4.5)$ & $2(9.5)$ & $1(7.7)$ & $0(0.0)$ \\
\hline Cord bleeding & $1(1.5)$ & $1(4.8)$ & $0(0.0)$ & $0(0.0)$ \\
\hline Congenital anomalies & $4(6.1)$ & $0(0.0)$ & $1(7.7)$ & $3(9.4)$ \\
\hline Low birth weight & $4(6.1)$ & $0(0.0)$ & $1(7.7)$ & $3(9.4)$ \\
\hline Neonatal Jaundice & $7(10.6)$ & $3(14.3)$ & $2(15.4)$ & $2(6.3)$ \\
\hline Birth trauma & $1(1.5)$ & $0(0.0)$ & $0(0.0)$ & $1(3.1)$ \\
\hline Neonatal hypoglycaemia & $1(1.5)$ & $0(0.0)$ & $0(0.0)$ & $1(3.1)$ \\
\hline
\end{tabular}

Of the different scoring systems, in this study, the one modified by Anand B et was used. ${ }^{4}$ This scoring system had been modified from questionnaire system initially proposed by Coopland et al. ${ }^{4}$ This scoring system involves three different aspects - medical risk factors, past obstetric factors and present obstetric factors. It has included some newer risk factors considering the knowledge of natural history of many new diseases. ${ }^{4}$ Few risk factors like multiple pregnancies which was not included in this scoring system was incorporated in our scoring. This system seemed the most appropriate in the present day obstetric practice and hence has been used in this study.

In our study, $67.3 \%$ women belonged to low risk, $20 \%$ to high risk and $12.7 \%$ to extremely high risk group. This was almost same to finding of study conducted by Anand B et al, whose scoring system was used in our study. They have reported $64.3 \%$ women in low risk group, $24.2 \%$ in high risk and $11.5 \%$ in extremely high risk group. ${ }^{4}$ Other studies conducted in Nepal have reported prevalence of 15 to $25 \% .{ }^{2,3,21}$ Studies using Dutta and Das scoring system reported prevalence of high risk pregnancy to range from 20 to $30 \%$ and that of moderate risk pregnancy to range from 15 to $33 \%$. ${ }^{9,0,22}$ Other studies using various other scoring systems have a wide variance in prevalence of high risk pregnancy-18 to $33 \%$. $^{5,6,7,23,24}$ The variance in the prevalence is due to different criteria and tools used for stratification of pregnancy into high risk groups and due to different study population and study setting.

In our study, in about $30 \%$ of the pregnant women, there were no risk factors at all and were scored zero. However, based on the stratifications system used in this study, they belonged to low risk group ( score 0 to 3 ). Study conducted by Jain et al also found that $30 \%$ of women had no risk factors at all. ${ }^{24}$ However, different studies have reported that 2 to $48 \%$ of pregnant women had no risk factors and scored zero. $^{10,22,25}$ The difference could be due to different setting in which the studies were conducted.

On risk stratification, there were women, who had only one risk factor while others have multiple risk factors. The common risk factors in our study were abortion (22\%), previous cesarean section (20.6\%), hypertensive disorders in pregnancy $(15.4 \%)$, oligohydramnios $(9.7 \%)$, anemia (5.7\%), extreme age at pregnancy (7.4\%), malpresentation at term $(4.9 \%)$, intrauterine growth restriction $(2.5 \%)$. Bernard et al also reported abortion, previous cesarean section, anemia, hypertensive disorders, malpresentation as their common risk factors during risk stratification of high risk pregnancies. ${ }^{22}$ Similar were the risk factors in study conducted by Anand B et al. ${ }^{4}$ Maternal age was the commonest risk factor in another study. ${ }^{7}$ Previous cesarean section is a common obstetric event that can complicate pregnancy outcome. With increasing cesarean section rates worldwide, presence of this risk factor was very common in many other studies including ours. ${ }^{2,522,25}$ This has been one of many indications leading to increased cesarean section rate in any institute and same held true in ours as well.

In terms of ethnicity, place of their residence, educational and occupational status, distribution of women in low risk, high risk and extremely high risk appeared to be similar in this study. Bernard also reported no difference in different risk groups in terms of religion and socioeconomic status. ${ }^{22}$ There are few other studies which have shown illiteracy and low socioeconomic status to be positively associated with high risk factors. ${ }^{6,25}$ All women had antenatal care even though the number of visits was less than four. Majority of the women in all three groups had more than four antenatal visits. Most of them had been getting antenatal care in tertiary level care either at our centre or outside. A hospital based study similar to ours however reported that $77 \%$ in the high risk group were unbooked compared to $20 \%$ of the low risk group."

In this study, cesarean deliveries were significantly more in high risk (77.9\%) and extremely high risk pregnancy ( $89.9 \%)$ compared to low risk pregnancy $(51 \%)$ with p-value $<0.001$. Operative deliveries were significantly common in high risk pregnancy groups in other studies as well. ${ }^{4,5,7,9}$ Cesarean section rate in high risk pregnancies ranged from $68 \%$ to $82 \%$ as shown in our study. ${ }^{4,5}$ High overall cesarean section in our study is high because almost $35 \%$ women belonged to high risk groups and cesarean section in both these high risk groups were very high ( $77.9 \%$ and $89.9 \%$ ).

Maternal complications were also statistically significant in extremely high risk and high risk groups compared to low risk groups in our study. About ten percent of extremely high risk pregnancy and $7.9 \%$ of high risk group developed complications. Postpartum haemorrhage and urinary complications were the common complications. Severe complications like Postpartum hemorrhage requiring peripartum hysterectomy, morbidly adherent placenta were seen in extremely high risk pregnancy and two cases of rectus sheath haematoma developed in high risk pregnancy. Obstetric haemorrhage requiring blood transfusion was more common in high risk pregnancies in another study as in our study. ${ }^{4}$

A study conducted in Nepal also showed that serious maternal morbidity was four times more common in high risk pregnancy compared low risk pregnancy. ${ }^{21}$ Another study also reported increased maternal complications in high risk pregnancy. ${ }^{9}$ Duration of hospital stay in our study 
was more in extremely high risk pregnancy and high risk pregnancy compared to low risk pregnancy. This was statistically significant. Similar finding was reported by Anand B et al. ${ }^{4}$

Perinatal outcome in terms of low birth weight, Apgar score less than 7 at 1 and 5 minutes and need for NICU admission and perinatal deaths were analyzed. The perinatal outcome was poor in high risk pregnancies compared to low risk pregnancy. Birth weight of newborns below 2500gm was more on extremely high risk $(60 \%)$ compared to high risk $(26 \%)$ and low risk pregnancy (15\%). This was statistically significant. Other studies on perinatal outcome of the high risk pregnancy also showed significantly higher percentage of neonates with birth weight below 2500 gms in high risk pregnancies. ${ }^{4,5,7,9,10}$ Apgar score below 7 at 1 and 5 minutes was more common in extremely high risk pregnancy compared to high risk and low risk pregnancies in our study; similar to findings of the other studies. ${ }^{4,10,23}$ Prematurity was not analyzed as it was one of the risk factors used in the scoring system. Prematurity was reported to be more common in high risk pregnancy in various studies. ${ }^{4,7,10,23}$

One third of the neonates required NICU admission in the extremely high risk group compared to $9.2 \%$ and $4.5 \%$ neonates in high risk and low risk pregnancy respectively. Commonest indication for admission was prematurity especially in extremely high risk and high risk groups- $62.5 \%$ and $30.8 \%$ respectively compared to 4.8 percent in low risk group. Neonatal sepsis was more common in the low risk and high risk groups. Birth asphyxia was only present in 14.3\% of low risk and $7.7 \%$ high risk pregnancy in contrary to findings of study done by Kolluru et al. ${ }^{9}$ NICU admission was found to be significantly more for high risk pregnancies in another study. ${ }^{4}$

Perinatal deaths (stillbirths and early neonatal deaths) were significantly more in extremely high risk pregnancy compared to high risk and low risk groups. Similar results were seen in the other studies with increased perinatal mortality in the high risk pregnancies. ${ }^{4,5,7,9,23,24}$

\section{CONCLUSION}

Almost one-third of pregnant women were high risk pregnancies with previous abortions and previous cesarean section, preterm labour being common risk factors during risk stratification. Maternal morbidity in terms of operative deliveries, maternal complications and hospital stay were increased in the high risk pregnancies. Likewise, neonatal outcome - low birth weight, low Apgar score at 1 and 5 minutes, need for NICU admission and perinatal mortality was increased in the high risk pregnancy compared to low risk pregnancy.

Hence, antenatal risk scoring system seems to be useful in predicting the women at risk of developing poor maternal and perinatal outcome.

\section{RECOMMENDATIONS}

Antenatal scoring is a risk assessment system that should be used during routine antenatal care to stratify women into different risk groups. This will ensure that high risk women receive timely and appropriate care so that adverse pregnancy outcomes are prevented. Utilizing this system, primary health care facilities with limited resources can make timely referrals while tertiary care centres can make different protocols for managing the risk factors to ensure better outcome for mother and new born.

\section{LIMITATIONS OF THE STUDY}

This was a small study limited to tertiary care referral centre. Larger study integrating both community as well as hospital settings will produce more meaningful result so that screening tool like this could be developed and recommended for countrywide use.

\section{ACKNOWLEDGEMENTS}

We would like to extend our gratitude to all patients who participated in the study. We would like to thank everyone in the department of Obstetrics and Gynaecology department for their constant support. We would especially like to acknowledge Ms Seema Subedi (data scientist), for all her help and support in the process of data analysis.

\section{CONFLICT OF INTEREST}

There is no conflict of interest in this study.

\section{FINANCIAL DISCLOSURE}

This study has been self-funded and was not external funding.

\section{REFERENCES}

1. Queenan JT, Spong CY, Lockwood CJ. Queenan's management of high-risk pregnancy: an evidencebased approach. 6 th ed. Oxford: Wiley-Blackwell; 2012:1

2. Singh AC, Khatri R, Rana SS, Malla R, Thapa S, Acharya I. High risk pregnancy and Fetal outcome at Shree Birendra Hospital. Journal of Society of Surgeons of Nepal. 2017 Dec 31;20(2):20-3.DOI: 10.3126/jssn.v20i2.24377

3. De A, De A, Fatima A, Sathian B, Asgil T, Finnegan R, Sharma JS. Prenatal Risk Score and Pregnancy Outcome: A Study in Nepal. Research Journal of Pharmaceutical biological and Chemical Science 2015 May $1 ; 6(3): 807-12$. ISSN: 09758585https:// www.researchgate. net/publication/276279474
4. Anand B, Mansukhani C, Gujral K, Pradhan M. Importance of developing a new modified high risk pregnancy scoring system. Indian Obstetrics and Gynaecology. 2017 Apr 12;7(1). ISSN:24556017 https://iog.org.in/index.php/iog/article/view/282

5. Jadhao AR, Gawade MD, Ughade SN. Outcome of pregnancy among high risk pregnancies in rural area of Nagpur, Maharashtra, Central India. Int J Community Med Public Health. 2017 Mar;4:628-33.DOI: 10.18203/2394-6040.ijcmph20170443

6. Jaideep KC, Prashant D, Girija A. Prevalence of high risk among pregnant women attending antenatal clinic in rural field practice area of Jawaharlal Nehru medical college, Belgavi, Karnataka, India. Int J Community Med Public Health. 2017;4:1257-9.DOI: 10.18203/ 23946040.ijcmph20171359 
7. Majella MG, Sarveswaran G, Krishnamoorthy $Y$, Sivaranjini K Arikrishnan K, Kumar SG. A longitudinal study on high risk pregnancy and its outcome among antenatal women attending rural primary health centre in Puducherry, South India. Journal of education and health promotion. 2019;8.PMID: 30815483

8. Kumar MP, Gnanadeep NV, Dixit UR, Patil PS. Prevalence of high risk pregnancy in rural Dharwad. J Dent Med Sci. 2015;14:29-32.DOI: 10.9790/0853-141062932

9. Kolluru V, Reddy A. Study of high risk scoring in pregnancy and perinatal outcome. Indian J Obstet Gynecol Res. 2016;3(4):4079.DOI: $10.18231 / 2394-2754.2016 .0024$

10. Mufti S, Mufti S. Identification of high risk pregnancy by a scoring system and its correlation with perinatal outcome. Indian Journal for the Practicing Doctor. 2008;5:1-7. http://www.indmedica.com/ journals. php?journalid=3\&issueid=124\&articleid=1643\&action=article

11. Dutta S, Das XS. Identification of high risk mothers by a scoring system and it's correlation with perinatal outcome. J Obstet Gynaecol India 1990;40:181-90

12. Malik S, Sinha S. High Risk Pregnancy. Biomedical Journal of Scientific \& Technical Research. 2017;1(5):1364-70.DOI: 10.26717/ BJSTR.2017.01.000438

13. Coopland AT, Peddle LJ, Baske TF, Rollwagen R, Simpson A, Parker E. A simplified antepartum high-risk pregnancy scoring form: statistical analysis of 5459 cases. Can Med Assoc J 1977; 116(9):999-1001. PMID: 858117

14. Hobel CJ, Hyvarinen MA, Okada DM, Oh W. Prenatal and intrapartum high-risk screening. I. Prediction of the high risk neonate. Am J ObstetGynecol 1973; 117(1):1-9.PMID: 4722373

15. Knox AJ, Sadler L, Pattison NS, Mantell CD, Mullins P. An obstetric scoring system: its development and application in obstetric management. Obstetrics and gynecology. 1993 Feb 1;81(2):1959.PMID: 8423949

16. Cho $\mathrm{CH}$. The identification of high-risk pregnancy, using a simplified antepartum risk-scoring system. TaehanKanho 1991; 30(3):49-65. PMID: 1921277
17. Nepal. Ministry of Health \& Population, New ERA (Firm, Kathmandu, Nepal), New ERA (Firm). Nepal demographic and health survey, 1996. Population Division, Ministry of Health and Population; 1997.

18. Nepal. Ministry of Health \& Population, New ERA (Firm, Kathmandu, Nepal), New ERA (Firm). Nepal demographic and health survey, 2016. Population Division, Ministry of Health and Population; 2017.

19. National Planning Commission. Sustainable Development Goals 2016-2030: National (Preliminary) Report. Kathmandu: National Planning Commission. 2015.

20. Haws RA, Yakoob MY, Soomro T, Menezes EV, Darmstadt GL, Bhutta ZA. Reducing stillbirths: screening and monitoring during pregnancy and labour. BMC pregnancy and childbirth. 2009 May;9(1):148.DOI:10.1186/1471-2393-9-S1-S5

21. Rajbanshi S, Norhayati MN, Nik Hazlina NH. High-risk pregnancies and their association with severe maternal morbidity in Nepal: A prospective cohort study. Plos one. 2020 Dec 28;15(12):e0244072. DOI: 10.1371/journal. pone.0244072

22. Bernard KJ, Baliga S. Risk status of pregnant women in rural areas of Belagavi: a cross sectional study. International Journal of Community Medicine and Public Health. 2019 Jun;6(6):2350. DOI:10.18203/ 2394-6040.ijcmph20192296

23. Ba'aqeel HS, Jabbar FA, Al-Meshari AA, Akiel AA, Kidess EA. Antenatal risk scoring form: statistical analysis of 1175 cases. Annals of Saudi Medicine. 1989 Mar;9(2):140-3.DOI: 10.5144/02564947.1989.140

24. Jain S, Anand S, Aherwar R. High risk scoring for prediction of pregnancy outcome: a prospective study. International Journal of Reproduction Contraception, Obstetrics and Gynecology. 2014 Sep;3:516-22.DOI: 10.5455/2320-1770.ijrcog20140910

25. Muhammed OA, Khalil NA, Omara MA, Khattab MA. Risky pregnancy among women attending a rural, family healthcare unit. Menoufia Medical Journal. 2017 Oct 1;30(4):1093.DOI: 10.4103/mmj. mmj_3_17 